\title{
CIDADANIA MULTIÉTNICA: ESBOÇO DE FORMAÇÃO DE UM ESTADO TRASNACIONAL PARA ALÉM DAS NACIONALIDADES
}

\author{
MULTIETHNIC CITIZENSHIP: DRAFT FORMATION OF A \\ TRANSNATIONAL STATE BEYOND NATIONALITIES
}

Recebido em 15/09/2017

Aprovado em 28/11/2017

\author{
ULISSES LEVY SILVÉRIO DOS REIS ${ }^{1}$ \\ SVEN PETERKE 2
}

RESUMO: O artigo apresenta considerações teóricas sobre a formação de um Estado transnacional no âmbito da Organização dos Estados Americanos capaz de viabilizar cidadania aos habitantes dos Estados-membros independentemente do gozo de uma nacionalidade específica. Tenta-se responder à questão: é possível garantir os direitos de cidadania dos apátridas independentemente do gozo de uma nacionalidade? A pesquisa é relevante porque os mecanismos do direito internacional dos direitos humanos relativos ao direito à nacionalidade não vêm conseguindo estancar o aparecimento de apátridas. Empregou-se o método dedutivo, com apoio em bibliografia das áreas das ciências jurídica e sociais, assim como da filosofia. Os referenciais teóricos principais são Arendt, Kant, Bauman e Habermas. O artigo divide-se em três momentos: no primeiro, apresenta-se como as duas Guerras Mundiais contribuíram para a criação de controles de migrantes nas fronteiras dos Estados e para medidas de desnacionalização; em seguida, será apresentada a perspectiva arendtiana do fracasso da dignidade humana para a proteção das minorias étnicas; no último, subdividido em três subpartes, será articulada, no campo teórico, a possibilidade de formação da categoria estatal citada anteriormente e como ela pode garantir a proteção dos direitos humanos dos apátridas. O trabalho demonstra que, apesar de não testado ainda no plano empírico, o Estado transnacional pode tornar-se uma realidade de proteção dos vulneráveis à medida em que pode proporcionar cidadania aos residentes nos territórios dos seus Estados-membros não pela em função do vínculo de nacionalidade, mas com base no critério do local de residência.

PALAVRAS-CHAVE: Apátridas. Guerras Mundiais. Estados Transnacionais. Organização dos Estados Americanos.

ABSTRACT: The article presents theoretical considerations about the formation of a transnational State within the Organization of American States capable of enabling citizenship to the inhabitants of the States-members regardless of the enjoyment of a particular nationality. It tries to answer the question: is it possible to guarantee citizenship rights to stateless regardless of the enjoyment of a nationality? The research is relevant because the mechanisms of international human rights law concerning the right to nationality have been unable to stop the emergence of stateless persons. It's used the deductive method, with support in literature of legal and social sciences, as well philosophy. The main theoretical references are Arendt, Kant, Bauman and Habermas. The article is divided into three stages: in first, it's presented as the two World Wars contributed to the creation of migrants controls at the frontiers of States and for denationalization measures; then, it will be presented to Arendt's thought about the failure of human dignity for the protection of ethnic minorities; in the latter, divided into three subparts, will be articulated, in theory, the possibility of formation of the state category mentioned above and how it can ensure the protection of human rights of stateless persons. The work shows that, although not yet tested empirically, the transnational State can become a protective reality to vulnerable people if it can provide citizenship to residents in the territories of its Member States not depending of the link of nationality, but based on the criterion of place of residence.

KEYWORDS: Statelessness. World Wars. Transnational States. Organization of American States.

1 Doutorando em Direito pelo Programa de Pós-Graduação em Direito da Universidade Federal do Ceará (PPGD/UFC). Mestre em Ciências Jurídicas pelo Programa de Pós-Graduação em Ciências Jurídicas da Universidade Federal da Paraíba (PPGCJ/UFPB). Especialista em Direitos Humanos e Bacharel em Direito pela Universidade do Estado do Rio Grande do Norte (UERN). Professor Assistente da Universidade Federal Rural do Semiárido (UFERSA)

2 Doutor em Ciências Jurídicas e Mestre em Assistência Humanitária Internacional pela Ruhr-Universität Bochum (Alemanha). Bacharel em Direito pela Christian-Albrecht-Universität zu Kiel (Alemanha). Professor Adjunto IV do Centro de Ciências Jurídicas da Universidade Federal da Paraíba (CCJ/UFPB). 


\section{INTRODUÇÃO}

O meio jurídico do Brasil, seja no âmbito prático ou acadêmico, costumeiramente não se debruça sobre a situação dos apátridas. A razão disso, muito provavelmente, se encontra no sistema concessório misto de nacionalidade elencado na Constituição Federal de 1988, o qual dá reduzida margem para geração de pessoas sem nacionalidade, sejam as nascidas no território nacional ou os filhos de pai ou mãe brasileiros que nascem no exterior.

Ocorre, porém, que o drama da carência de nacionalidade é concreto e, segundo dados do Alto Comissariado das Nações Unidas para os Refugiados (ACNUR), afeta cerca de quinze milhões de pessoas no mundo atualmente, conquanto não se tenha dados estatísticos precisos nesta mensuração (ONU, online). Embora existam tratados universais e regionais construídos com o fim de garantir o gozo da nacionalidade para todos os seres humanos ${ }^{3}$, bem como sejam incessantes os esforços dos órgãos de monitoramento/fiscalização judiciais e extrajudiciais da aplicação destes instrumentos normativos, o fato é que permanece a situação de violação dos direitos destas pessoas, como apontado pela agência especializada das Nações Unidas.

Tudo indica que a falha dos órgãos internacionais nesta missão se deve ao próprio modo como a solução do problema é pressuposta: pela concepção segundo a qual a garantia dos direitos humanos/fundamentais é corolário do gozo de uma nacionalidade. Esse trabalho, de teor nitidamente teórico, visa justamente inverter tal lógica e responder ao seguinte problema: é possível garantir os direitos de cidadania dos apátridas independentemente do gozo de uma nacionalidade (se sim, como)? É premente a necessidade de se encontrar nos campos acadêmico e político uma resposta para tal dilema, uma vez que os mecanismos dos Estados-nações, mesmo articulados internacionalmente, não parecem aptos, pelo menos a curto e médio prazo, a solucioná-lo.

A pesquisa é realizada no campo normativo. Foi construída com o método de abordagem dedutivo e com apoio em bibliografias dos campos das ciências jurídicas, da

\footnotetext{
3 No âmbito internacional, existem a Convenção sobre o Estatuto dos Apátridas de 1954 e a Convenção para a Redução dos Casos de Apatridia de 1961. Já no sistema europeu, há a Convenção Europeia sobre Nacionalidade de 1997 e a Convenção de Prevenção da Apatridia em Relação à Sucessão de Estados de 2006. Com relação ao sistema interamericano de proteção dos direitos humanos, o art. XIX da Declaração Americana dos Direitos e Deveres do Homem de 1948 (DADDH/1948) e o art. 20 da Convenção Americana sobre Direitos Humanos de 1969 (ConvADH/1969) contemplam a obrigação de os Estados conferirem as suas nacionalidades a todos os nascidos em seus territórios e a todos aqueles que corram o risco de não gozar de uma.
} 
sociologia e da filosofia. Os principais referenciais teóricos são Arendt, Kant, Bauman e Habermas.

Para encontrar a resposta à problemática apresentada, subdividiu-se o trabalho em três etapas. Na primeira, será trabalhada a perspectiva arendtiana com relação ao tratamento dado às minorias étnicas à época das Guerras Mundiais, o que implicou em medidas de desnacionalização realizadas especialmente pela Alemanha hitlerista e pela ex-União das Repúblicas Socialistas Soviéticas (URSS) stalinista; o segundo instante abordará o que a autora chamou de ponto de ruptura da dignidade humana frente à insuficiência dos mecanismos dos Estados-nações para garantir a proteção dos apátridas e demais vulneráveis presentes em seus territórios; já a última, subdividida em menores itens, tentará construir, pelo menos no campo teórico, a moldura de um Estado transnacional no qual seria possível a coexistência multiétnica baseada numa esfera pública normativa e discursiva comuns capaz de garantir os direitos de cidadania - inclusive dos apátridas - não mais pelo critério de titularidade da nacionalidade, mas sim com fundamento no local de residência do ser humano.

Embora não exista, pelo menos no campo médio de visão, a possibilidade de configuração de um Estado transnacional, a sua especulação vem ganhando corpo na academia. Certamente um dos pontos nos quais ele pode contribuir com uma melhor coexistência humana reside na garantia dos direitos de cidadania dos vulneráveis.

\section{O IMPACTO DAS GUERRAS MUNDIAIS NA DIFUSÃO DOS APÁTRIDAS}

Das obras que tratam sobre o contexto de formação dos apátridas no mundo, certamente a mais conhecida é a da filósofa judia Hannah Arendt. Talvez por ter sido uma apátrida que viveu como refugiada nos Estados Unidos da América (EUA) por mais de uma década até obter a sua naturalização, este tenha lhe sido um tema tão caro e ao qual dedicou várias reflexões em Origens do Totalitarismo, marco da filosofia política do século XX e instigador de debates que se expandem para todas as áreas das humanidades.

Alguns dos maiores saldos negativos da Primeira Guerra Mundial foram o alastramento da inflação e do desemprego por toda a Europa. As economias europeias, até então impávidas em razão da possibilidade de exploração dos recursos materiais fornecidos 
pelas ex-colônias, perderam as suas capacidades de sustentação e especialmente por força da destruição de fábricas, lares e instalações públicas e privadas ocorridas durante a conflagração ${ }^{4}$.

E não foram somente as economias que saíram dizimadas do conflito. As próprias estruturas políticas perderam as suas capacidades tradicionais de manutenção a partir do alastramento do processo de descolonização. Países que até então continham em seu interior povos de etnias diversificadas coabitando regularmente em função da pressão exercida pela metrópole não mais contavam com tal característica, principalmente no seio oriental europeu, na Ásia e na África, o que impulsionou o surgimento de conflitos intestinos.

O cenário apresentado deu ensejo à formação de estruturas políticas frágeis e ao ódio entre as nações coexistentes dentro dos territórios dos Estados. No momento em que foram colocados povos com etnias distintas dentro de um espaço geográfico comum e determinou-se que eles constituíssem uma base política una para a administração do seu governo, os chamados Estados artificiais (ARENDT, 2012, p. 372-375), as diferenças culturais falaram mais alto e geraram o ódio intestino 5 . Em regra, a etnia com maior número de pessoas dentro da comunidade não tinha interesse em respeitar a cultura, os costumes, a língua, a religião, dentre outros caracteres sociais das demais e se utilizava do Estado justamente para fulminar a possibilidade da diferença.

Essa conjuntura foi chancelada pelos países ocidentais ao firmar a Sociedade das Nações. A entidade, tentativa pós-Primeira Guerra Mundial de formar um órgão capaz de manter a paz e a estabilidade mundiais, patrocinou a criação desses Estados artificiais e elaborou, para ratificação pelos seus integrantes, os chamados Tratados de Minorias, ou seja, documentos pelos quais os governos se comprometiam em proteger as características culturais das etnias minoritárias existentes dentro dos seus territórios. No plano ideal, deveria o ente internacional cuidar das minorias em plano global, enquanto cabia aos signatários legislar

\footnotetext{
${ }^{4}$ Uma das primeiras manifestações do palco de instabilidade econômica apresentado na Europa foi a criação de sistemas burocratizados responsáveis por controlar rigidamente os fluxos migratórios. Até a Primeira Guerra Mundial, os Estados mantinham frouxos os laços relativos ao controle de entrada e saída de pessoas dos seus territórios, situação modificada a partir da exigência cada vez maior do passaporte e do visto (LAFER, 1988, p. 140).

5 Uma das características mais evidentes da artificialidade desses novos países pode ser vista fora da Europa, na África. Não raro veem-se contornos geográficos entre Estados que seguem exatamente os meridianos e os paralelos da terra, o que demonstra a inexistência de uma divisão baseada em critérios históricos, sociais, culturais, linguísticos etc.
} 
internamente de modo a garantir os seus direitos. Na prática, essa conjuntura foi solenemente ignorada pelos governos.

Afirma Hannah Arendt que, embora no campo discursivo os Estados editassem leis de proteção aos direitos humanos, estas não contemplavam os grupos minoritários, os quais tendiam a ser, no "melhor" dos casos, assimilados; ou, em outros, liquidados. Nesse contexto, a medida mais sombria tomada pelos Estados consistiu na desnacionalização de pessoas não integrantes da nação predominante, o que os isentava, pelo menos sob o paradigma da época, de ter de salvaguardar os interesses desses indivíduos. A configuração da nação, moldada em características culturais comuns, transformou-se em mecanismo de repulsa contra tudo o que caracterizasse o estrangeiro, o diferente, abrindo a porta para a exclusão das minorias étnicas e religiosas, em especial os judeus (HABERMAS, 2002, p. 127).

As medidas de desnacionalização preponderaram em Estados totalitários, especialmente na Alemanha, na Itália e na URSS (LAFER, 1988, p. 144). Não foi à toa que a pensadora conjecturou que uma das medidas pelas quais se poderia mensurar o nível de totalitarismo atingido por um governo consistia na aferição do alcance e da frequência de suas medidas de desnacionalização. Ao romper o vínculo de nacionalidade com os grupos minoritários, os governos deixavam os indivíduos sem ter lar ou para onde ir. Como maneira de tentarem alcançar a proteção de alguma entidade política, não raro essas pessoas imiscuíam-se em guerras civis existentes na Europa apoiando algum dos grupos beligerantes.

As leis de desnacionalização logo geraram milhões de indivíduos apátridas. Os tradicionais mecanismos da repatriação e da naturalização não foram capazes de solucionar o problema. O primeiro em razão de as pessoas já não terem lar para onde retornar. $\mathrm{O}$ segundo porque foi orquestrado de modo a amparar um ou outro caso individualmente, revelando-se imprestável quando acionado por milhares de pessoas simultaneamente.

A um só tempo, os apátridas perderam a proteção diplomática e o enquadramento na legalidade. Tornavam-se ilegais pelo só fato de existir. Verdadeiros foras-da-lei. Como não tinham vínculo regularizado com qualquer Estado, eram pessoas indesejadas onde quer que estivessem. Para se ter uma noção precisa do infortúnio que os acometia, apenas quando cometia algum crime e era recluso pelo governo é que algum membro deste grupo se igualizava com os nacionais no padrão da legalidade, pois lhe era ofertado o devido processo 
regular, o acesso a um advogado, a oportunidade de queixar-se contra maus tratos na cadeia, dentre outras premissas 6.

Aliado a isso, criou-se na Europa uma rede de troca de informações entre agências policiais responsável por identificar e segregar apátridas. Foi a era do chamado Estado Policial (ARENDT, 2012, p. 391-393). Organizações atuando por meios secretos de modo a minar a possibilidade de mobilização das pessoas privadas de nacionalidade, bem como de aplacar qualquer insatisfação porventura existente contra o cenário dominante.

No arremate cruel desta situação adveio a proposta de exterminação dos judeus arquitetada por Hitler, conhecida não sem dose de sarcasmo como Solução Final. Primeiro, leis de desnacionalização retiraram os vínculos existentes entre essa população e o Estado; após, foram eles expulsos do país na condição de apátridas; ao remate, procedeu-se com o seu reagrupamento do lugar onde estivessem para o envio aos campos de extermínio (ARENDT, 2012, p. 394)7 . O mais famoso, Auschwitz, localizado no sul da Polônia, apesar de não se contar com dados, foi responsável pelo extermínio de, no mínimo, um milhão de pessoas8.

\footnotetext{
6 "Aqui se observa a grande crise de sentido na qual submergiam os Direitos Humanos já naquele período. A forma mais indicada de melhorar a condição mundana de diversas pessoas era o cometimento de crimes. Quando pequenos furtos favorecem a posição legal de alguém, não precisamos temer em afirmar que esta pessoa está plenamente destituída de direitos humanos." (PEREIRA e SILVA FILHO, 2008, p. 70) A outra possibilidade de destacamento da condição perpétua de ilegalidade promovida pela apatridia consistia na genialidade do indivíduo. Quando a pessoa detinha conhecimentos acima da média e essa capacidade poderia servir de algum modo ao Estado, ela tinha os seus direitos respeitados como os demais nacionais. Sobre a situação do criminoso, eis as palavras da autora: "A melhor forma de determinar se uma pessoa foi expulsa do âmbito da lei é perguntar se, para ela, seria melhor cometer um crime. Se um pequeno furto pode melhorar a sua posição legal, pelo menos temporariamente, podemos estar certos de que foi destituída dos direitos humanos. Pois o crime passa a ser, então, a melhor forma de recuperação de certa igualdade humana, mesmo que ela seja reconhecida como exceção à norma. $\mathrm{O}$ fato - importante - é que a lei prevê essa exceção. Como criminoso, mesmo um apátrida não será tratado pior que outro criminoso, isto é, será tratado como qualquer outra pessoa nas mesmas condições. Só como transgressor da lei pode o apátrida ser protegido pela lei. Enquanto durem o julgamento e o pronunciamento da sua sentença, estará a salvo daquele domínio arbitrário da polícia, contra o qual não existem advogados nem apelações. O mesmo homem que ontem estava na prisão devido à sua mera presença no mundo, que não tinha quaisquer direitos e vivia sob ameaça de deportação, ou era enviado sem sentença e sem julgamento para algum tipo de internação por haver tentado trabalhar e a ganhar a vida, pode tornar-se quase um cidadão completo graças a um pequeno roubo. Mesmo que não tenha um vintém, pode agora conseguir advogado, queixar-se contra os carcereiros e ser ouvido com respeito. Já não é o refugo da terra: é suficientemente importante para ser informado de todos os detalhes da lei sob a qual será julgado. Ele torna-se pessoa respeitável." (ARENDT, 2012, p. 390)
}

${ }^{7}$ Não havia possibilidade, para os apátridas, de tentar sobreviver ao julgo do Estado nazista. $\mathrm{O}$ ato de viver foi criminalizado. Eis a primordial manifestação da indiferença para com a humanidade (PEREIRA, 2014, p. 115).

8 Recente documentário produzido pela rede televisiva inglesa BBC traz um retrato fiel, inclusive permeado com entrevistas de ex-detentos e ex-soldados da guarda pessoal hitlerista SS (Schutzstaffel), sobre o terror vivenciado em Auschwitz e os mecanismos cada vez mais sofisticados para a realização dos extermínios, os quais evoluíram dos tiros com armas de fogo até a utilização das famigeradas câmaras de gás (AUSCHWITZ, 2005). 


\section{O PONTO DE RUPTURA DA DIGNIDADE HUMANA E A INSUFICIÊNCIA DOS MECANISMOS DO ESTADO-NAÇÃO PARAA PROTEÇÃO DAS MINORIAS}

O saldo reflexivo das questões de fato analisadas por Hannah Arendt consistiu na identificação do ponto de ruptura dos direitos humanos no período que mediou as duas grandes guerras do século XX. Tornou-se claro para ela que a mera legalização de direitos humanos dentro de comunidades políticas somada à ratificação de tratados sem o efetivo intento de cumpri-los não era capaz de assegurar o respeito à alteridade das minorias e dos privados de nacionalidade. A herança da Declaração Francesa de 1789, que tão bem diferenciou o homem do cidadão, evidenciou a distinção de tratamento entre ambos. Foi o retumbante fracasso da dignidade humana (PEREIRA, 2014, p. 118-124).

O ser humano considerado cidadão, integrante da comunidade política, membro da etnia majoritária que norteia a ação do Estado, é digno de proteção e respeito. Pode acessar os serviços estatais e, em caso de insatisfação, reclamar oficialmente uma providência corretiva. O apátrida, privado de nacionalidade num mundo em que já não existem territórios livres de exercício dalgum poder soberano, não tem lugar para onde ir ou a quem recorrer. Não possui capacidade de articulação política.A sua voz é muda9.

\footnotetext{
9 O seguinte trecho, apesar de extenso, é um dos maiores tributos escritos acerca do estudo das consequências da apatridia no cenário humano: "A calamidade dos que não têm direitos não decorre do fato de terem sido privados da vida, da liberdade ou da procura da felicidade, nem da igualdade perante a lei ou da liberdade de opinião - fórmulas que se destinavam a resolver problemas dentro de certas comunidades - mas do fato de já não pertencerem a qualquer comunidade. Sua situação angustiante não resulta do fato de não serem iguais perante a lei, mas sim de não existirem mais leis para eles; não de serem oprimidos, mas de não haver ninguém mais que se interesse por eles, nem que seja para oprimi-los. Só no último estágio de um longo processo o seu direito à vida é ameaçado; só se permanecerem absolutamente 'supérfluos', se não se puder encontrar ninguém para 'reclamá-los', as suas vidas podem correr perigo. Os próprios nazistas começaram a sua exterminação dos judeus privando-os, primeiro, de toda condição legal (isto é, da condição de cidadãos de segunda classe) e separando-os do mundo para ajuntá-los em guetos e campos de concentração; e, antes de acionarem as câmaras de gás, haviam apalpado cuidadosamente o terreno e verificado, para sua satisfação, que nenhum país reclamava aquela gente. $\mathrm{O}$ importante é que se criou uma condição de completa privação de direitos antes que o direito à vida fosse ameaçado.

[...] A privação fundamental dos direitos humanos manifesta-se, em primeiro e acima de tudo, na privação de um lugar no mundo que torne a opinião significativa e a ação eficaz. Algo mais fundamental do que a liberdade e a justiça, que são os direitos do cidadão, está em jogo quando deixa de ser natural que um homem pertença à comunidade em que nasceu, e quando o não pertencer a ela não é um ato da sua livre escolha, ou quando está numa situação em que, a não ser que cometa um crime, receberá um tratamento independente do que ele faça ou deixe de fazer. Esse extremo, e nada mais, é a situação dos que são privados dos seus direitos humanos. São privados não do seu direito à liberdade, mas do direito à ação; não do direito de pensarem o que quiserem, mas do direito de opinarem. Privilégios (em alguns casos), injustiças (na maioria das vezes), benção ou ruínas lhes serão dados ao sabor do acaso e sem qualquer relação com o que fazem, fizeram ou venham a fazer.

Só conseguimos perceber a existência de um direito a ter direitos (e isto significa viver numa estrutura onde se é julgado pelas ações e opiniões) e de um direito a pertencer a algum tipo de comunidade organizada, quando surgiram milhões de pessoas que haviam perdido esses direitos e não podiam recupera-los devido à nova situação política global. O problema não é que essa calamidade tenha surgido não de alguma falta de civilização, atraso ou simples tirania, mas sim que ela não pudesse ser reparada, porque já não há qualquer lugar 'incivilizado' na terra, pois, queiramos ou não, já começamos realmente a viver num Mundo Único. Só com uma humanidade completamente organizada, a perda do lar e da condição política de um homem pode equivaler à sua expulsão da humanidade.” (ARENDT, 2012, p. 402-404) Nessa passagem, Arendt lida com a categoria da ação, que consiste, grosso modo, na relevância do agir pessoal a partir da inserção do ser humano no discurso travado no espaço público. É essa possibilidade de intercomunicação que torna a pessoa relevante no contexto social. O conceito foi pormenorizado pela autora, em contraposição ao animal laborans e ao homo faber, em obra posterior (ARENDT, 2014).
} 
É por isso que se firmou como uma das maiores contribuições da leitura da obra mencionada o conceito de cidadania como o direito a ter direitos ${ }^{10}$. Eis o desafio dos Estados e da Organização das Nações Unidas (ONU) no pós-Segunda Guerra Mundial: conferir direitos aos indivíduos independentemente da existência do vínculo de nacionalidade ${ }^{11}$. Mas não basta a mera previsão disso em declarações de direitos, como houve nos Tratados de Minorias promovidos pela Sociedade das Nações. É imprescindível o encontro de uma forma eficaz de assegurar esse respeito, o que encaminha para uma reflexão acerca da composição dos elementos do Estado.

Para a autora, enquanto os Estados forem regidos pelo trinômio clássico governoterritório-povo12, a situação dos sem pátria não será solucionada (ARENDT, 2012, p. 394; LAFER, 1988, p. 158). O emblemático caso de Israel foi paradigmático. Para se outorgar um território a uma nação sem Estado, foi preciso expulsar milhares de árabes do local onde haviam se instalado há muito tempo. Mais uma vez ressurge o drama dos refugiados e apátridas, desta feita protagonizado pelo povo palestino. Sempre alguma minoria será sacrificada pela incapacidade da maioria de aceitar o outro, o diferente.

10 Apesar do inquestionável peso da análise arendtiana à construção do conceito de cidadania após as experiências das Guerras Mundiais, concordamos com Sorto (2011, p. 105) quanto à sua insuficiência frente ao paradigma dos documentos internacionais de proteção dos direitos humanos firmados no pós-1948. Para a caracterização da cidadania, devem-se somar aos direitos os deveres das pessoas para com as comunidades em que estão inseridas, como preveem de formas variadas as Declarações Americana (arts. XXIX-XXXVIII) e Universal (art. 29) dos Direitos Humanos, a Convenção Americana dos Direitos Humanos (art. 32) e o texto constitucional brasileiro (art. $5^{\circ}$ ). Não obstante o complemento do conceito de cidadania demarcado em Origens do Totalitarismo, a lacuna apontada é incapaz de obscurecer a validade do raciocínio de ruptura dos direitos humanos articulado na obra.

${ }^{11}$ Dentre esses direitos, é indispensável o asseguramento da possibilidade de mesmo os sem pátria interferirem na condução da vida política através da sua ação, inclusive por meio do voto, modo tradicional de concretização dos direitos políticos. A cidadania tem relação direta com a participação no processo de tomada das decisões coletivas. Sem que isso seja assegurado, não se estará falando de democracia muito menos de cidadania (GUERRA, 2012, p. 67).

12 Embora se use nesse trabalho indiferentemente os termos povo e nação, não se desconhece que se tratam de vocábulos que, originariamente, remontaram a significações distintas. Entretanto, a fungibilidade do uso ancorase na obra $O$ que é o Terceiro Estado?, na qual o teórico Emmanuel Joseph Sieyès (1988) funde tais conceitos de modo a qualificar a nação como depositária única e exclusiva da autoridade soberana, designando-a com base em elementos comuns: língua, valores culturais, interesses etc. Para uma diferenciação, cf. Habermas (2002, p. 124): 'No uso político da linguagem, os conceitos 'nação' e 'povo' têm a mesma extensão. Para além da fixação jurídica, no entanto, 'nação' também tem o significado de uma comunidade política marcada por uma ascendência comum, ao menos por uma língua, cultura e história em comum. Um povo transforma-se em 'nação' nesse sentido histórico apenas sob a forma concreta de uma forma de vida em especial. Os dois componentes, que estão enleados em conceitos como 'Estado nacional' ou 'nação de cidadãos de um mesmo Estado', remetemse a dois processos que de modo algum decorreram paralelamente na história - à formação de Estados, por um lado, e de nações, por outro.” 
A constatação que se extrai da análise feita consiste na insuficiência do modelo histórico de Estado-nação que se sagrou vitorioso nas Revoluções Americana e Francesa para fins de albergar e respeitar no seu território, simultaneamente, os interesses e os direitos da nação predominante e das minorias étnicas, nestas inclusos os apátridas. Embora se reconheça a importância contextual do trabalho de teóricos como Hobbes, Bodin, Locke, Hume, Rousseau e Montesquieu, responsáveis, cada um ao seu modo, pela construção do conceito moderno de Estado-nação, o qual fez residir na nação toda a soberania (art. $3^{\circ}$ da Declaração Francesa de 1789) (RANIERI, 2013, p. 108) ${ }^{13}$, verificam-se as insuficiências desta construção no cenário pós-1945.

Outro autor que analisa as mudanças ocorridas entre as metades dos séculos XIX para $\mathrm{XX}$ e as suas repercussões na tarefa estatal de proteger os interesses da população do seu território é Ferrajoli (2002, p. 27-38). Trabalhando o conceito de soberania, aponta ele que a passagem secular apresentou duas modificações para esse atributo do poder estatal. Enquanto no plano interno ele é cada vez mais limitado por textos constitucionais que garantem os direitos fundamentais, no plano externo expande-se agressivamente.

Para o italiano, a limitação interna, ramo que interessa agora, não abrange os interesses de todas as pessoas localizadas dentro do Estado. Limita-se a garantir os direitos dos componentes do substrato social da nação, do povo, o qual é integrado ao Estado através da concepção orgânica que prevaleceu por muitos anos. Os outros, compreendendo estrangeiros e minorias, não estão contemplados nesse grupo.

Pergunta-se, então: qual a consequência da manutenção dessa situação de inércia quanto ao asseguramento dos direitos dos apátridas? A resposta certamente não é das melhores. Em Estados como o Brasil, p. ex., que não consegue garantir dignidade humana e justiça social para os seus próprios nacionais, a vinda eventual de apátridas de outras localidades possibilitada pela facilitação dos meios de locomoção atuais é um fato que pode

\footnotetext{
13 Tão arraigada é a concepção de que o Estado deve servir aos interesses do povo - ou nação - predominante em seu território que Bonavides (2008, p. 57) chegou mesmo a identifica-lo com a própria essência da Constituição: "O Povo é a Constituição, a Constituição é o povo; os dois, com o acréscimo da soberania, compõem a santíssima trindade política do poder. Mas não de qualquer poder, senão daquele que traz a inviolabilidade, a grandeza ética, a fundamentalidade da Democracia participativa".
} 
agravar a crise social. Além das classes desprivilegiadas que já existem, outras poderiam somar-se e piorar o quadro nacional em termos de acesso a direitos básicos ${ }^{14}$.

Conjectura-se que a resposta para o problema dessas pessoas, em âmbito global, passa pela remodelação do tradicional modelo de Estado-nação. Apenas a construção de uma arena pública política na qual todos possam exercer a sua influência na construção dos rumos da coletividade, independente da comunhão de uma cultura em particular, será capaz de criar a solidariedade necessária para o pertencimento humano junto ao semelhante e ao diferente. Como alude Habermas (2001, p. 27-28), não se pode negar a contribuição dos teóricos clássicos e a importância do conceito de Estado-nação para a evolução da humanidade no contexto da Idade Moderna, mas é nítida a sua insuficiência para a proteção das minorias atuais, uma vez que a sua concepção tinha outro propósito.

\section{CONFERINDO CIDADANIA AOS APÁTRIDAS NUM PERCURSO DE KANT A HABERMAS}

\subsection{A INSUFICIÊNCIA DO DIREITO DE HOSPITALIDADE KANTIANO NO CONTEXTO DO ESTADO-NAÇÃO}

Ao que tudo indica, os instrumentos jurídicos titularizados pelos Estados são insuficientes para enfrentar o desafio inclusivo que se apresenta com relação aos apátridas (e também aos migrantes em geral). Os óbices impostos pela globalização econômica, movimento responsável por abalar os alicerces governamentais de todos os países, minam a capacidade de oferta de serviços estatais afetos ao Estado de Bem-Estar Social, gerando uma diminuição de empregos e recursos disponíveis, o que comumente desencadeia sentimentos de xenofobia.

14 Habermas (2002, p. 141) ilustra as possíveis consequências de manutenção da privação de direitos das camadas sociais minoritárias dentro de um Estado: "Em uma visão de longo alcance, há pelo menos três consequências inevitáveis. Uma subclassse gera tensões sociais cuja descarga se dá com revoltas despropositadas e autodestrutivas, que só podem ser controladas com recursos repressivos. A construção de penitenciárias, a organização da segurança interna em geral revelam-se uma indústria em crescimento. Além disso, a desolação social e a miserabilização física não se deixam limitar localmente. O veneno do gueto também age sobre a infraestrutura dos centros urbanos, atinge regiões inteiras e se fixa nos poros de toda a sociedade. Por fim, isso tem como consequência uma erosão moral da sociedade, que necessariamente danifica toda e qualquer coletividade republicana em seu âmago universalista. Pois decisões de maioria estabelecidas de maneira formalmente correta e que apenas refletem os temores pela manutenção do status e reflexos de autoafirmação por parte de uma classe média ameaçada pela descensão social corroem a legitimidade dos procedimentos e instituições. Por essa via, desvirtua-se a verdadeira conquista do Estado nacional, que tratou de integrar sua população por meio da participação democrática." 
Uma possível solução para essa crise consiste na rearticulação dos instrumentos jurídicos estatais em busca da construção de um Estado transnacional, o qual associaria os interesses das populações em nível interno e regional ou global, a depender da capacidade de integração alcançada. Para que tal modelo tenha êxito, diversos desafios devem ser superados. Quanto ao problema dos apátridas, haja vista principalmente a forma como o sistema interamericano de direitos humanos vem tentando guarnecê-los dos seus direitos, concebe-se que um modelo transnacional de Estado em torno da Organização dos Estados Americanos (OEA) pode ser a saída para tal desafio.

Sem a pretensão de debater todas as correntes sociológicas que atualmente versam sobre o estudo de entidades desta natureza, analisar-se-á as possibilidades de conformação de um Estado transnacional em torno da organização regional americana e como isso beneficiaria os apátridas. Para tanto, será necessário fazer um resgate das ideias de Kant e Habermas, intercalando a análise sociológica de Bauman nesse contexto.

A razão que levou Kant a escrever o opúsculo da paz perpétua não foi tratar sobre a inclusão de estrangeiros nos territórios dos Estados, preocupação ignorada na agenda política internacional em fins do século XVIII, mas sim conjurar um protótipo de tratado capaz de estabelecer relações pacíficas duradouras entre estes ${ }^{15}$. O filósofo endossa o posicionamento de Hobbes no sentido de alertar que, entre os seres humanos no estado de natureza, reinava a barbárie e a chacina do homem contra o homem (KANT, 2010, p. 23). A formação do Estado seria a via racional para fazerem-se cessar tais hostilidades no âmbito interno de cada população; no contexto interestatal, a conformação das entidades sob uma normatização comum é o caminho por ele apontado.

A virada metodológica promovida por Kant quanto ao Direito Internacional Público foi atribuir como função desta tecnologia o propósito de garantir a paz ${ }^{16}$. Por meio dos artigos preliminares, definitivos e os suplementos da paz perpétua, apresentou ele um modelo de

15 Antes de Kant, outras obras já haviam sido escritas acerca do tema da pacificação social da humanidade, como, p. ex., o projeto europeu de paz perpétua do Abade de Saint-Pierre (2003).

16 Sobre o desenvolvimento do Direito Internacional antes de Kant, cf. Galindo (2014, p. 82): "Na doutrina anterior a Kant, a guerra não era vista como uma antítese do próprio direito. Ao contrário, ela era legalizada. Não é à toa que o primeiro item do Livro I de Jure Belli Ac Pacis, de Grocius, já deixava claro que 'a guerra é empreendida em prol da paz' e '[a] própria guerra nos levará em seguida à paz como a seu último fim'. A doutrina da guerra justa não apenas permitia o uso da guerra como resposta a um ilícito, ela tornava a guerra um instrumento de suporte e efetividade do direito. É justamente em virtude do apoio, recorrente ao seu tempo, às doutrinas de autores como Grocius, mas também Puffendorf e Vattel, para 'justificar uma ofensiva de guerra', que Kant chama esses 'pais' do direito internacional de 'tristes consoladores'.” 
tratado capaz, pelo menos em tese, de assegurar a paz. Para isso, determinou que toda constituição estatal deveria ser republicana, pois, colocando-se nas mãos das populações a tarefa de decidir se deveria o Estado entrar em guerra, as decisões são tomadas com mais comedimento e reflexão (KANT, 2010, p. 26-27) ${ }^{17}$.

Segundo ainda o autor (2010, p. 36), assim como ocorre com relação à formação dos Estados, a melhor maneira para que cessassem as guerras entre povos seria a evolução destes para a conformação de um Estado dos povos regido pela mesma e única lei. Entretanto, admite o filósofo que este projeto é inatingível, dada a natureza conflituosa dos seres humanos. Em substituição a isso, propõe ele, em seu segundo artigo definitivo, que o Direito das Gentes deve alicerçar-se numa federação de Estados livres, entidade que, pelo menos até então, jamais existiu 18 .

Aliada a essa hipótese de federalização dos Estados, Kant incluiu no terceiro artigo definitivo do seu tratado o chamado direito de hospitalidade ${ }^{19}$. Mas esse direito, não filantropia, segundo a reflexão contida na paz perpétua, é assaz limitado. Isso por várias razões, todas delimitadas pela leitura da própria obra (KANT, 2010, p. 37-38): i) caso o estrangeiro não se comporte pacificamente, poderá ser hostilizado com a retirada do território; ii) a sua fundamentação limita-se apenas ao fato de a Terra ser esférica e ninguém poder dela evadir-se, não tendo o filósofo feito menção à solidariedade ou aos direitos humanos; e iii) esse direito de hospitalidade é limitado à autorização dos recém-chegados para o estabelecimento de um intercâmbio com os habitantes do local onde se encontra, não havendo menção alguma à possibilidade de sua integração na comunidade em termos sociopolíticos.

17 De maneira distinta do que ocorre quando as decisões sobre a guerra são fruto da vontade individual e muitas vezes egoísta do Príncipe, o povo sabe melhor avaliar as consequências da guerra, pois os seus custos humanitários e financeiros recaem sobre a população no geral. Corroborando com essa leitura, diz Soraya Nour (2013, p. 43): “A constituição republicana é então apresentada como funcionalmente pacífica porque é a única que expressa a vontade dos que assumem os encargos da guerra e que por isso, provavelmente, não serão a seu favor. Portanto, não só é a única constituição em acordo com a liberdade como também é a única que favorece uma ordem internacional pacífica. A paz depende então da vontade do povo.”

18 A teorização kantiana, por ser reflexo do seu tempo e contextualizada historicamente, não foi capaz de, por si só, garantir a paz na humanidade. É que os séculos XIX e XX flagraram a existência de conflitos neocoloniais, duas Guerras Mundiais (1914-1918 e 1939-1945) e a chamada Guerra Fria com diversos conflitos episódicos ao redor do globo que geraram um saldo de milhões de mortos. É evidente o contrassenso entre o avanço da doutrina jurídica e a prática dos Estados, pois, embora a guerra tenha passado a ser formalmente considerada um ilícito a partir de 1945 (Carta da ONU, art. $2^{\circ}, \S 4^{\circ}$ ), mais comportamentos bélicos foram registrados e com maior potencial de ceifar vidas. Para informações mais detalhadas dos conflitos do século XX, cf. HOBSBAWM, 1995.

19 Cf. o teor do terceiro artigo definitivo para a paz perpétua: "O direito cosmopolita deve ser limitado às condições da hospitalidade universal." 
Em outra obra, Kant qualifica como atributo indissociável da cidadania a capacidade humana de influir, por meio dos instrumentos criados pela comunidade, na tomada de decisões legislativas responsáveis por ordenar o seu relacionamento com o Estado e com as demais pessoas. São atributos jurídicos incindíveis da cidadania a liberdade de não obedecer a nenhuma lei senão a que foi consentida pelo indivíduo, a igualdade entre os cidadãos e a independência civil (KANT, 2011, p. 179-180).

Apesar de o filósofo ter inaugurado o "direito cosmopolita" ao considerar o indivíduo como membro de uma sociedade mundial que lhe deve hospitalidade (NOUR, 2013, p. 168; HABERMAS, 2002, p. 185), este atributo é insuficiente para garantir cidadania aos estrangeiros no contexto de sua própria obra como um todo, pois resta condicionado ao caráter inofensivo deste indivíduo e não garante a sua participação comunitária por meio do exercício dos direitos políticos ${ }^{20}$. Essa permissão de estadia não induz uma agregação, mas uma tolerância com o outro. A tolerância, sinônimo de condescendência, nada mais é que imposição da razão do mais forte21.

O pensamento kantiano também foi alvo da armadilha do tempo ${ }^{22}$. Não pode ele prever os danos oriundos da matriz formadora dos Estados-nações a partir da vitória deste modelo de soberania nas revoluções americana e francesa (HABERMAS, 2001, p. 80).

A corporificação do Estado foi possível a partir do final do século XVIII à medida em que restou homogeneizado o seu elemento povo no conceito de nação. Essa identificação interindividual coletiva produziu uma ligação entre as pessoas que até então não existia. A

20 Em contradição à necessidade de se conceder direitos políticos aos apátridas como maneira de inclui-los na sociedade nacional e garantir a satisfação plena da sua personalidade, verifica-se atualmente a existência de indivíduos que, embora gozem da prerrogativa participativa por meio do voto e dos demais instrumentos democráticos concebidos nas constituições, recusam-se a fazerem uso de tais mecanismos por motivos em geral ligados às desilusões provocadas pela incapacidade dos Estados de cumprirem as promessas do Estado de BemEstar Social. São os chamados cidadãos difíceis (MENDONÇA, 2012, p. 57-63).

${ }^{21}$ Lúcidas são as palavras de Pereira (2013, p. 317) sobre o tema: "A ideia de tolerância não pode ser vista como a panaceia ou o fundamento decisivo para o prisma de violência, luta e guerra, que ainda se insurge no mundo. Só toleramos aquilo que, em sede inicial, não toleraríamos. Assim, quando tolero ainda tenho a última palavra e decido se sou clemente com a diferença que me traz desconforto. Sou um juiz no tribunal da relação. Ao tolerar o outro assumo um patamar de hierarquia. Ainda sou senhor da razão e modelo o outro àquilo que minha representação cognitiva conduz. Impeço-o de sua outridade. Despedaço aquilo que primordialmente configura a possibilidade do Encontro.”

22 A crítica habermasiana sobre o projeto de paz perpétua de Kant é de igual sentido: "Naturalmente, Kant desenvolve essa ideia segundo os conceitos do direito racional e no horizonte da experiência de sua época. As duas coisas afastam-nos de Kant. Com o imerecido 'saber melhor' alardeado pelas gerações mais jovens, reconhecemos hoje que a construção sugerida por Kant enfrenta dificuldades conceituas e já não se mostra mais adequada a nossas experiências históricas.” (HABERMAS, 2002, p. 186) 
integração dos nacionais legitimou democraticamente os corpos estatais. A percepção comum necessária para tal empreendimento foi cristalizada a partir de elementos como a língua, a história e a cultura, no que muito contribuíram os intelectuais. Países que não possuíam essa identificação comum mais ampla se utilizaram da religião em seu lugar, como os EUA. O problema desta estruturação social é que se torna ela presa fácil de governos inescrupulosos capazes de, ao inflamar o sentimento de nacionalismo, incitar a sua população à ojeriza coletiva, como demonstrado anteriormente (HABERMAS, 1995, p. 91-95)23.

A homogeneização étnico-cultural capaz de democratizar o aparelho de sustentação do Estado teve como viés negativo a opressão e a exclusão das minorias étnicas que coabitassem o seu território, bem como a criação de obstáculos à imigração de indivíduos alheios ao seu substrato comum. Para Bauman (1999, p. 70), qualquer resquício de autodeterminação provindo de minorias nacionais a partir de uma incipiente autossuficiência militar, econômica ou cultural foram suprimidas pelo estabelecimento do Estado-nacional soberano.

A instauração de comunidades políticas homogêneas exclui apátridas, pois a ideia do direito a ter direitos arendtiana pressupõe o pertencimento à nação (BENHABIB, 2012, p. $23)^{24}$. O mais vil efeito dessa configuração é que eventuais opressões aos direitos de estrangeiros presentes dentro do território do Estado-nação não são objeto de sanção eficaz por parte de qualquer outro ator da sociedade internacional (PEREIRA, 2012, p. 75-75), em especial no ambiente anterior à segunda metade do século $\mathrm{XX}$, quando inexistiam órgãos internacionais de proteção dos direitos humanos.

Para Habermas (2002, p. 257), o fetiche à homogeneidade hostiliza a imigração pelo receio de que a afluência de indivíduos que não comungam do substrato comum possa alterar a composição populacional do ponto de vista étnico-cultural. Segundo essa concepção, a diluição promovida pelo afluxo de estrangeiros representaria um enfraquecimento da comunidade e do Estado-nação. Como estratégia de destruição do multiculturalismo, governos, ao longo das épocas, promoveram aculturação de etnias minoritárias pela imposição

\footnotetext{
23 Essa constatação da capacidade de manipulação das populações dos Estados a partir do uso do nacionalismo desmente também outra premissa kantiana: a de que as constituições republicanas seriam eficazes para evitar a guerra (HABERMAS, 2002, p. 192-193).

24 Essa ideia de autossuficiência do Estado-nação para a garantia dos direitos deu ensejo à ideia do nacionalismo metodológico, concepção segundo a qual o espaço social estatalmente determinado é o ambiente em que se refletem as condições essenciais para o diagnóstico da sociedade como um todo (PAULO, 2015, p. 07).
} 
forçada da língua, da religião e dos costumes da maioria, assim como limpezas étnicas por meio da segregação física (PEREIRA e SILVA FILHO, 2008, p. 78).

É possível verificar a confirmação do apartheid promovido pelo paradigma da nacionalidade no paradoxo de países como os EUA e os componentes da União Europeia. Apesar de serem eles os maiores injetores de capital no ACNUR, são também os que mais maltratam migrantes em situação irregular (PEREIRA, 2014, p. 82-83). O governo francês, à época do mandato do Presidente Nicolas Sarkozy, chegou a institucionalizar um programa oficial de expulsão de apátridas ciganos dando em contrapartida trezentos euros para cada adulto e cem euros por criança (FERNANDES, online) ${ }^{25}$. A política de acolhimento de refugiados e apátridas nos Estados Unidos sofreu forte mudança após o atentado ao World Trade Center em 2001. O país, conhecido por acolher pessoas em busca de segurança (dentre elas, personalidades da ciência como Hans Kelsen, Hannah Arendt e Albert Einstein, os dois últimos apátridas por vários anos), impõe atualmente restrições ao ingresso e à estadia em seu território com base na segurança nacional e na prevenção ao terrorismo (PEREIRA, 2014, p. 90-96).

Em violação ao art. XIII da Declaração Universal dos Direitos Humanos de 1948²6, os Estados concebidos a partir da ficção da nacionalidade selecionam os indivíduos que pretendem incorporar ao seu território a partir dos seus interesses culturais e econômicos. Os irregulares, geralmente movidos por razões sociais, de perseguição ou desastres climáticos, recebem apenas a violência estatal. $\mathrm{O}$ apátrida sofre o drama de, a qualquer momento, ser expulso do local onde se encontra, ainda que tenha contribuído socialmente por anos executando trabalhos não desejados pelos nacionais (JAROCHINSKI SILVA, 2014, p. 326).

O feixe protetivo oriundo do direito internacional dos direitos humanos, que pressupõe a adesão dos ordenamentos estatais às suas diretrizes, parece capaz de enfrentar o problema dos apátridas em longo prazo, mas ressente-se da formação de arquiteturas jurídicas hábeis, da incorporação dos seus elementos pelos Estados e da eficácia das suas normas. Para ficar só

\footnotetext{
25 A prática efetuada pelo Estado francês, por incrível que possa parecer, se coaduna com a Diretiva de Retorno implementada pela União Europeia aprovada pelo seu Parlamento em meados de 2008 e cuja implantação ocorreu em 2010 pelos Estados-membros. Esse documento institucionaliza o tratamento do tema migratório em tais países como afeto à segurança nacional e incentiva a expulsão de indivíduos em situação irregular do território da entidade (LEITE, 2010, p. 61-70).
}

26 Art. XIII. 1. Todo homem tem direito à liberdade de locomoção e residência dentro das fronteiras de cada Estado. 2. Todo o homem tem o direito de deixar qualquer país, inclusive o próprio, e a este regressar. 
num exemplo desta insuficiência, nenhuma das convenções sobre os apátridas de 1954 ou 1961 estabeleceram mecanismos de monitoramento internacional e de incorporação pelos Estados para a definição procedimental do status de apátrida do indivíduo e de sua permanência no território do país (JUBILUT e APOLINÁRIO, 2010, p. 284-285)27.

\subsection{EFEITOS DA ECONOMIA GLOBALIZADA E DA QUEBRA DO ESTADO DE BEM- ESTAR SOCIAL SOBRE OS APÁTRIDAS}

Não foi apenas o modo de formação dos Estados-nacionais que deu ensejo ao quadro atual de fragilidade quanto à inclusão de apátridas e estrangeiros em geral. Fenômeno peculiar da passagem dos séculos XX para o XXI, a globalização de matrizes econômica e comunicacional, ao mesmo tempo em que eliminou a percepção espaço-temporal de distâncias entre os países, impôs uma nova forma comportamental para os governos pautada não mais no atendimento dos interesses dos cidadãos, mas sim na subserviência ao mercado externo.

Na contramarcha do ocorrido no pós-Segunda Guerra Mundial, quando dinamizaram as suas economias de forma proativa para fomentar o crescimento dos países e a recuperação dos seus cidadãos, os Estados, com a globalização, tiveram contra si espoliada tal prerrogativa de ação. No veredito de Bauman (1999, p. 73-74), os governos tornaram-se executores de forças que não podem ou mesmo esperam controlar politicamente. Nenhum Estado deve tentar intervir em áreas econômicas de maneira dirigente, sob pena de atrair a ira do mercado internacional.

Para o sociólogo polonês, a globalização tem preferência por Estados fracos que necessitam do auxílio dos seus aparatos internacionais (bancos mundiais, fundos internacionais etc.) para sobreviver, pois eles não possuem respaldo suficiente para questionar

\footnotetext{
27 Os autores citados expõem que o surgimento de novos sujeitos dentro do contexto migratório, especialmente a partir do século XX, traz novos problemas cujas soluções não foram arquitetadas pelas entidades internacionais ou pelos Estados. Excepcionando a situação dos refugiados, já bastante desenvolvida no âmbito universal e nos ordenamentos estatais, os demais grupos carecem de proteção, como os deslocados internos, os que estão em condição análoga à dos refugiados, os deslocados ambientais e os migrantes por questões econômicas, sociais, culturais e de desenvolvimento. O texto diz que a tentativa de enquadramento de todas as categorias de migrantes em situação de risco na de refugiados, como comumente se faz, é prejudicial por banalizar um instituto que já alcançou um nível de maturidade relevante. Sustentam ainda que é desnecessária a criação de um novo ramo internacionalista como um Direito Internacional da Migração, bastando, para a proteção das categorias diversas de migrantes, que sejam aperfeiçoados os ramos existentes do direito internacional dos direitos humanos.
} 
as diretrizes desta nova ordem mundial. Quanto aos governos fortes, ela tenta minar os seus alicerces por meio do incentivo à desregulamentação das ações de promoção do bem-estar individual, tais como as legislações trabalhistas, previdenciárias, assistenciais etc. No período histórico analisado acima, os Estados exerciam funções dominantes sobre os seus territórios e população. Hoje, são os mercados que ditam os rumos das economias ${ }^{28}$.

O influxo globalizatório não cria vítimas apenas fora da comunidade nacional. No plano interno, os governos não mais podem preocupar-se com a promoção do bem-estar dos seus cidadãos, pois todas as suas ações são voltadas ao aumento da competitividade econômica. A lógica do binômio capitalismo/globalização é a do lucro. Ao passo em que minguam as fontes de solidariedade, avolumam-se camadas sociais desprotegidas e marginalizadas que, por serem segregadas, não detém condições de saírem sozinhas do estado de miséria. Habermas (1995, p. 99-100) identifica três consequências deste cenário: i) a criação de uma underclass geradora de tensões sociais e que apenas pode ser refreada por ações violentas; ii) a privação social que permeia todos os poros das cidades numa veloz disseminação; e iii) a castração da voz participativa de tais pessoas traz consigo uma erosão da moralidade pública capaz de minar a força integrativa da democracia.

Esse fenômeno econômico atinge negativamente os direitos sociais e promove a disseminação da desigualdade. A união entre os dirigentes dos Estados e as elites financeiras nacionais e internacionais difunde a concepção segundo a qual, para o asseguramento do crescimento e da estabilidade econômica, é necessária a redução dos custos salariais, o que implica na flexibilização das legislações protetivas do trabalhador e na diminuição dos direitos de natureza social, dentre outras medidas neoliberais (GUERRA, 2012, p. 124-125).

Quando tal cenário alia-se à modernização das tecnologias produtivas capazes de substituir a mão-de-obra humana por ferramentas informatizadas, ocorre a diminuição de

\footnotetext{
28 Paulo (2015, p. 18-19) vai mais além ao aduzir que o principal efeito da globalização não é apenas retirar a política econômica da agenda dos Estados, mas sim excluir a própria política do âmbito dos órgãos internos. Diz o autor que hoje são as empresas multinacionais, cada vez mais sofisticadas em termos de governança, os entes responsáveis pela condução dos assuntos de interesse de todas as populações do planeta. Cf. "Nota-se o definhamento do Estado na medida em que este não se reconhece que sob a bandeira da 'globalização' se encontra de 'mãos atadas', e, neste contexto, não é somente o Estado, mas também os sindicatos e a política. Políticos de vários partidos, surpresos e fascinados diante do poder da globalização rebelam-se, uns aos outros, procurando 'soluções', mas permanecendo de 'olhos vendados' diante da extração que o fenômeno da 'globalização' engendrou para o desmoronamento do Estado e da própria política. As empresas transnacionais detêm o poder que outrora pertencia aos Estados. O Estado social foi vítima de ataques aos centros vitais da sociedade moderna no qual estava fundado. Este processo teve seu caminho aberto sem insurreições, sem mudanças legislativas ou mesmo constitucionais e meramente com o curso normal."
} 


\section{TEVISTA ACADÊMICA

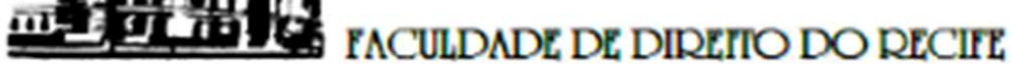

postos de trabalho ocupados por pessoas. A precarização das relações laborais somada à escassez de empregos cria uma competitividade interna dentro dos países entre os próprios nacionais. Somar a tal conjuntura o elemento estrangeiro apenas aguça a crise. Sem empregos e com precárias legislações protetivas, as populações dos países considerados estáveis apresentam uma reação chauvinista até certo ponto esperada contra os imigrantes de todas as naturezas que buscam melhores condições de vida em seus territórios (HABERMAS, 2011, p. 298).

Mesmo em condições precárias, os postos de trabalho são cobiçados por todas as pessoas por se constituírem na única salvaguarda contra a miséria. Para muitos, é melhor receber um salário-mínimo que postular do Estado, cada vez mais reduzido por políticas neoliberais, alguma garantia de renda. Se a competição por emprego já é grande entre os nacionais, ela inflaciona quando se adicionam os elementos apátridas, refugiados e migrantes econômicos.

Ao mesmo tempo em que são empurrados para o fundo do poço a fim de desregulamentarem as suas legislações de proteção, os Estados são reféns do sistema capitalista global e sofrem erosões em suas capacidades de determinar as suas políticas econômicas. Habermas (2001, p. 92) constata nesse cenário uma perda de solidariedade que se manifesta principalmente por meio de reações xenofóbicas contra tudo que possa ser qualificado como estrangeiro, seja por causas etnocêntricas, culturais, de credo, por coloração da pele etc., pois aquele que vem de fora apenas sacrifica mais ainda a capacidade interna de sustentação.

As relações humanas foram monetarizadas de tal modo que até mesmo a permissão de ingresso dentro de um país está condicionada à possibilidade lucrativa trazida pelo acolhimento do estrangeiro (PEREIRA, 2012, p. 73). O acesso de um migrante obedece à lógica do capital. Somente faz sentido o acolhimento do indivíduo que agrega algum benefício financeiro em termos de investimento ou consumo.

A facilidade de deslocamento advinda da globalização não funciona sob a mesma lógica para os migrantes que buscam comida. As massas de pobres e famintos desafiam as consciências dos que propagam a possibilidade de livre circulação, mas que a ressalvam 
quando se trata dos indesejados (BAUMAN, 1999, p. 84) ${ }^{29}$. O tratamento destes últimos difere substancialmente da hospedagem garantida aos ricos.

O século XXI trouxe um complicador aos interesses dos Estados nesta questão migratória: a facilidade de deslocamento. Se antes era fácil manter a segregação entre Estados-nações porque não se imaginava que latino-americanos, africanos e asiáticos pudessem invadir em massa a América do Norte e a Europa, hoje o cenário não é o mesmo. As migrações contemporâneas são fluidas e escancaram a porosidade das fronteiras. Ainda que os Estados do norte desenvolvido respondam ao fenômeno com militarização e criminalização, ela não deixa de crescer e expor o fatalismo da crise (BENHABIB, 2012, p. 28-30).

Os Estados, além de serem erodidos externamente a partir dos interesses das multinacionais, implodem silenciosamente em decorrência da existência de conflitos dentro dos seus territórios. A população local não aceita partilhar os recursos materiais com os que vêm de fora. E isso não se restringe apenas aos países com nações homogêneas, ocorrendo até mesmo em realidades multiétnicas como o Brasil.

\subsection{POSSIBILIDADE DE O ESTADO TRANSNACIONAL SER A SOLUÇÃO INCLUSIVA NECESSÁRIA À CONSOLIDAÇÃO DOS DIREITOS HUMANOS DOS APÁTRIDAS}

Com base em Hannah Arendt ${ }^{30}$, compreende-se que somente o paradigma da multietnicidade, aliado à inclusão legitimada discursiva e normativamente, pode fornecer as respostas adequadas ao acolhimento de apátridas e estrangeiros.

Sob o modelo do Estado-nação, enquanto não for construída espontaneamente pelos Estados legislações de proteção aos estrangeiros, terão eles apenas obrigações morais de aceitar estas pessoas. Habermas (2002, p. 260-261) fundamenta esse dever nos fatos históricos relacionados à política colonial europeia imprescindível ao impulsionamento das economias

\footnotetext{
${ }^{29}$ Nessa obra, o polonês se utiliza de suas peculiares metáforas para discernir entre os migrantes que gozam de privilegiada posição social - medida em termos econômicos - dos que não a compactuam. Os primeiros ele qualifica de turistas, enquanto os demais são chamados de vagabundos. Ambos, ao coabitarem um mundo que obedece à lógica do capital e por estarem respectivamente guarnecidos e desprivilegiados de comunicação pelo idioma do dinheiro, são consumidores, mas, enquanto o primeiro é satisfeito, o segundo é um frustrado.

30 Segundo a autora (ARENDT, 2014, p. 10), é justamente a diferença que nos humaniza: “A pluralidade é a condição da ação humana porque somos todos iguais, isto é, humanos, de um modo tal que ninguém jamais é igual a qualquer outro que viveu, vive ou viverá."
} 
dos países daquele continente. Sempre a Europa tirou proveito dos fluxos migratórios, seja enviando indivíduos para as colônias ou selecionando trabalhadores para os seus postos de emprego. Nesse momento em que o mundo precisa de uma contrapartida, talvez seja a hora de estender os braços.

Mas essa obrigação moral é insuficiente à garantia de direitos e ao asseguramento da inclusão, pois somente tem vazão em cenários de estabilidade política e econômica. Quando surgem períodos de crise, o recrudescimento das prestações estatais tem por alvo prioritário, em regra, os que não gozam da nacionalidade ofertada pelo Estado. É assim atualmente no Brasil, onde se verificam abusos nos direitos dos migrantes haitianos e sírios; na Europa, em que o fluxo de estrangeiros oriundos de conflitos armados africanos e do Oriente Médio enseja a edificação de mais e mais barreiras de acesso aos países.

A solução para esse etnocentrismo de Estado passa pela proposta habermasiana de formação de Estados transnacionais. Se tal modelo já soou implausível em outros momentos históricos, assim não é mais. Países como Suíça e EUA revelam a possibilidade de formações estatais a partir não de uma origem étnica ou linguística comuns a todos os indivíduos. O que houve em seus territórios foi a formação de culturas políticas matizadas sob princípios constitucionais de teor liberal. Esse perfil jurídico-político é capaz de agudizar não apenas a tolerância para com a variedade, mas também a integração entre as diferentes formas de vida coexistentes numa sociedade multicultural (HABERMAS, 2011, p. 289).

Exemplos desta natureza não se veem apenas no Norte desenvolvido. O Brasil também é reconhecidamente um Estado multicultural. Desde a chegada dos colonizadores, os elementos europeus das mais variadas etnias (portugueses, holandeses, alemães, italianos etc.) partilham a formação do espaço territorial com as populações tradicionais indígenas, com os negros advindos da exploração da mão-de-obra escrava, com asiáticos, com migrantes latinoamericanos, dentre várias outras formações etnográficas que coabitam o seu vasto território ${ }^{31}$.

Se coexistem Estados-nação com Estados multiculturais, percebe-se que as identidades não são um dado biológico ou fadadas a uma formação pré-política. Elas podem ser construídas. As interações históricas e sociais entre populações que não comungam da mesma

31 Claro que não se pode igualizar as experiências de formação multicultural de Estados como o Brasil e os EUA com países em que o arquétipo do Estado-nação se formou a partir dos elementos tradicionais povo, governo e território, como, p. ex., a França ou a Inglaterra. Nestes últimos, a passagem de um Estado-nacional para um Estado multicultural é tarefa mais dolorosa por ter que enfrentar a barreira da tradição; nos primeiros, a verdade é que esse padrão clássico jamais existiu. 
etnia ou substrato cultural podem construí-las, destruí-las, distribuí-las ou reconstruí-las. Segundo Pereira (2012, p. 78) 32 a percepção do racionalismo moderno de que as identidades resultam de uma identificação entre sujeito e Estado está equivocada. A pureza identitária é que se constitui num problema quando levada ao extremo e sustenta discursos xenofóbicos e políticas de criminalização do outro.

Benhabib (2012, p. 38-39) enxerga na sociedade atual marcos de reconfiguração da cidadania oriundos desta nova forma de interação entre as pessoas. Cada vez mais este conceito se afasta do pertencimento à nacionalidade do Estado e caminha em direção à cidadania de residência. Os laços dos indivíduos não mais se prendem ao aparato governamental, mas ao local onde residem. Reflexo disso é a ascensão de um ativismo urbano cada vez mais interessado em temas que afetam indiferentemente nacionais e estrangeiros, como os direitos das mulheres, a educação de língua secundária para as crianças, o trabalho para os migrantes, as preocupações ambientais, dentre outros assuntos.

A reflexão trazida por esses autores apresenta uma luz contra o processo de ruptura das redes de solidariedade provinda da globalização (GUERRA, 2012, p. 126). A evolução dos Estados multiculturais, que ainda restringem a integração de apátridas e estrangeiros quando as suas legislações são ineficientes ou lacunosas no asseguramento do direito à nacionalidade ou quanto ao acesso aos serviços públicos (caso do Brasil)33, é capaz de ensejar uma rearticulação intergovernamental em prol da edificação de Estados transnacionais. Essa transnacionalidade, se aplicada no âmbito da OEA, pode garantir, pelo menos em médio e longo prazo, a solução dos entraves vivenciados pelos indivíduos sem nacionalidade na América.

\footnotetext{
32 Habermas (2001, p. 127-129) concorda com esse posicionamento ao sustentar que os meios jurídicos e de comunicação de massa fornecem os substratos necessários para a construção de uma identidade entre indivíduos que não comungam de uma homogeneidade cultural. Em caminho que coaduna com tal pensamento, Ferrajoli (2002, p. 56-58) argumenta que a reestruturação da soberania dos Estados passa pela formação de um constitucionalismo mundial que assegure a todos os residentes em qualquer país os direitos afetos à cidadania independentemente do gozo da nacionalidade.

33 Um retrato da precariedade do acesso aos serviços públicos brasileiros por parte de migrantes em situação irregular pode ser vista em CASTAMANN, 2006.
} 
Existem várias formas de se pensar esse Estado transnacional ${ }^{34}$, mas a análise aqui empreendida será limitada à proposta habermasiana. Utilizando a União Europeia como laboratório, o sociólogo alemão enxerga a possibilidade de criação de uma cidadania compartilhada. As pessoas componentes da União são, ao mesmo tempo, cidadãos europeus e cidadãos de algum dos Estados-nacionais. A sua atuação política deve levar em consideração tanto os interesses do país em que se encontram como o do continente como um todo. Os atuais contextos multiculturais tornam cada vez mais importante esse desvencilhamento da cidadania da homogeneidade dos padrões culturais ou étnicos. A socialização da cultura política comum gera laços que envolvem todas as pessoas.

O que Habermas (2001, p. 126-127) apregoa como modelo de Estado transnacional não é um achatamento das identidades nacionais, mas uma busca pela sua coexistência democratizada a partir do espaço discursivo comum. Para isso, é necessária a extensão de uma solidariedade entre os nacionais de cada Estado-membro de forma que cada um sinta-se responsável pela condição cívico-social dos demais. A solidariedade cívica deve ser transportada do âmbito local para o regional. A partir dessa modificação, certos direitos de soberania dos Estados-nações devem ser transferidos para um governo transnacional que seria responsável por regulamentar matérias capazes de atingir todos os membros simultaneamente, o que pode envolver diretrizes civis, políticas, sociais e econômicas. Haveria, no entanto, uma margem local de apreciação de matérias reservadas aos Estados-membros não atingida pela política comum do órgão regional. Os chamados assuntos internos permanecem resguardados para a comunidade local. O sucesso deste padrão depende também da constituição de uma Carta, similar a uma Constituição, na qual se assegurem os direitos dos habitantes deste Estado transnacional.

Se aplicada esta concepção no âmbito da OEA, a expectativa é que, paulatinamente, os indivíduos de um dos seus Estados sintam-se responsáveis não apenas pelos concidadãos nacionais, mas também pelo destino de todos os integrantes do Estado transnacional americano. Além disso, não mais importaria se algum estrangeiro presente na região detém ou não nacionalidade, pois é dever da Organização instituir políticas públicas em seu favor de

\footnotetext{
34 Ao analisar a proposta de Ulrich Beck, Paulo (2015, p. 23-26) destaca como seus alicerces a alienação de partículas de soberania pelos Estados-nações, sem necessidade de cessão de território, pois o Estado transnacional está dentro e além de cada país. Para o sucesso do projeto, é necessária a assimilação dos princípios do pacifismo jurídico e do federalismo.
} 
modo a concretizar os seus direitos de cidadania independentemente do gozo de alguma nacionalidade.

Para isso, será valiosa a contribuição do aparato de proteção aos direitos humanos já existentes. A Comissão e a Corte Interamericanas de Direitos Humanos teriam um papel relevante a contribuir com a Assembleia Geral da OEA no sentido de fiscalizar a implementação das diretrizes da DADDH/1948 e da ConvADH/1969, haja vista o teor garantista de ambas. Claro que, para uma melhor efetivação desta tarefa, é essencial a adesão de todos os Estados-membros ao sistema protetivo interamericano, sobretudo dos EUA.

A implantação deste Estado transnacional interamericano inevitavelmente promoveria a reconfiguração da cidadania dos indivíduos presentes em seus Estados-membros. As pessoas vinculadas a tal entidade devem ser instrumentalizadas do poder de fiscalizar a sua governabilidade a partir da eleição de mandatários políticos não apenas dos Estadosmembros, mas também dos indivíduos, compondo-se um Parlamento com a mais ampla representação possível. Como este cenário ainda não é tangível ao olhar próximo, não se dará maiores detalhes sobre tais possíveis mecanismos, mas ressalta-se a necessidade de que tais estruturas de governança e coordenação sejam transparentes e responsáveis (BENHABIB, 2012, p. 37).

Essa modificação, se feita de acordo com o parâmetro ora apresentado e não a partir das práticas xenofóbicas infelizmente ainda vistas na União Europeia, promoveria uma alteração para melhor quanto ao tratamento de apátridas no continente em razão da criação de um sentimento de pertencimento não a partir da comunhão de um padrão cultural prévio, mas sim por meio do exercício participativo e do estabelecimento de diretrizes jurídicas comuns 35 .

Ao garantir o gozo dos direitos básicos a todos independente da nacionalidade, e principalmente na sua carência, o Estado transnacional da OEA criaria as condições necessárias para a construção de um debate público em que todos os participantes (brasileiros, argentinos, estadunidenses, haitianos, chilenos, migrantes regulares ou irregulares, apátridas, refugiados, asilados etc.) participariam em igualdade de condições para a construção de uma

35 Os parâmetros jurídicos desse Estado transnacional devem ser capazes de assegurar não apenas a participação política dos seus membros, que é insuficiente por si só quanto à promoção da cidadania vista holisticamente. É imprescindível também que o debate público contemple alternativas plausíveis para a solução da pobreza e da desigualdade num esforço transnacional (GUERRA, 2012, p. 145). 
perspectiva comum, o que evitaria a tomada das medidas imperialistas tão presentes na agenda dos direitos humanos.

\section{CONCLUSÃO}

Na tentativa de ultrapassar a concepção tradicional baseada na formação dos Estadosnações de que os governos devem garantir a cidadania dos seus nacionais e, com relação aos não incluídos neste conjunto étnico, guardar apenas as obrigações morais, apresentou-se a proposta de um Estado transnacional no âmbito da OEA. Essa formação contribuiria com a proteção dos apátridas ao assegurar os seus direitos não pelo critério da nacionalidade, mas do local de residência dentro dos Estados-membros.

Esse pensamento surgiu a partir da constatação de que o modo como o direito internacional dos direitos humanos vem tentando garantir os direitos de cidadania dos sem nacionalidade não vem gerando maiores êxitos, haja vista a situação de apatridia ser ostentada ainda por cerca de quinze milhões de pessoas. A atuação dos ACNUR e dos órgãos regionais de proteção dos direitos humanos, que alicerçam as suas atuações no dever dos Estados de garantir o vínculo de nacionalidade àqueles que não os possui para, só então, garantir os seus direitos de cidadania, costuma esbarrar na prática chauvinista dos entes estatais, que se consideram soberanos nessa matéria.

A formação de um Estado transnacional nos moldes pensados por Habermas, não territorial, mas composto por concessões de parcelas de soberania em prol de uma instância superior aos governos nacionais responsável por regulamentar matérias comuns aos seus componentes e capaz de articular-se em pé de igualdade com as multinacionais, apresenta-se como uma proposta promissora para a recuperação da capacidade de autonomia dos Estados. Esse autogoverno, embora partilhado, representaria uma configuração capaz de rejuvenescer, sob outro formato, o poder de autodeterminação espoliado destes últimos.

Um Estado transnacional interamericano, para proteger os apátridas, imprescinde de garantir os direitos humanos destas pessoas independentemente da existência do vínculo de nacionalidade. As suas diretrizes devem assegurar tal salvaguarda pelo critério do local de residência. Suas instâncias de representação cidadã devem proporcionar o direito de escolha de representantes em níveis positivo e negativo para os sem nacionalidade, pois um 
parlamento desta natureza ultrapassa os vínculos dos indivíduos com os Estados-membros. Seria esta uma esfera pública discursiva e normativa comum que contaria com apoio da Comissão e da Corte Interamericana de Direitos Humanos para a fiscalização da garantia dos diretos humanos das pessoas nele presentes.

Este cenário pode parecer distante ao olhar próximo, mas a velocidade das transformações sociais não ocorre com o mesmo relógio cronológico dos séculos passados. Poucos anos foram suficientes para que a União Europeia formalizasse a sua integração por meio de vários mecanismos unificados (tribunal, moeda, passaporte, cidadania etc.). A América muito bem pode seguir os seus passos, mas acertando naqueles pontos não bem tratados pela Europa, como a migração.

\section{REFERÊNCIAS}

ARENDT, Hannah. A Condição Humana. Tradução Roberto Raposo; revisão técnica e apresentação Adriano Correia. - 12 ed. rev. - Rio de Janeiro: Forense Universitária, 2014.

Letras, 2012.

Origens do Totalitarismo. Tradução Roberto Raposo. - São Paulo: Companhia das

AUSCHWITZ: The Nazis and the "Final Solution". Produção de Mary Mazur. Dirigido por Laurence Rees e Catherine Tatge. Reino Unido: BBC One, 2005. 2 DVDs.

BAUMAN, Zygmunt. Globalização: as consequências humanas. Tradução Marcus Penchel. - Rio de Janeiro: Zahar, 1999.

BENHABIB, Seyla. O declínio da soberania ou a emergência de normas cosmopolitas? Repensando a cidadania em tempos voláteis. Civitas, Porto Alegre, v. 12, n. 1, jan./abr. 2012, p. 20-46.

BONAVIDES, Paulo. Teoria do Estado. - $7^{\mathrm{a}}$ ed., rev. e ampl. - São Paulo: Malheiros, 2008.

CASTAMANN, Daniela. Acesso aos serviços de saúde em municípios brasileiros limítrofes de fronteiras com os países do MERCOSUL. Dissertação (Mestrado em Serviço Social e Política Social) - Universidade Estadual de Londrina. - Londrina, 2006.

FERNANDES, Daniela. BBC. França expulsa 79 ciganos com programa que oferece 300 euros. Disponível em <http://www.bbc.com/portuguese/noticias/ 2010/08/100818_franca_ciganos_dg.shtml>.Acesso em: 12 fev. 2016

FERRAJOLI, Luigi. A soberania no mundo moderno: nascimento e crise do Estado nacional. Tradução de Carlo Coccioli e Márcio Lauria Filho; revisão da tradução por Karina Jannini. - São Paulo: Martins Fontes, 2002.

GALINDO, G. R. B. A Paz (ainda) pela Jurisdição Compulsória?. Revista Brasileira de Política Internacional (Impresso), v. 57, n. 2, Brasília, Jul./Dez. 2014, p. 82-98.

GUERRA, Sidney. Direitos Humanos \& Cidadania. - São Paulo: Atlas, 2012. 
HABERMAS, Jürgen. A constelação pós-nacional: ensaios políticos. Tradução de Márcio Seligmann Silva. - São Paulo: Littera Mundi, 2001.

A inclusão do outro: estudos de teoria política. Tradução de George Sperber e Paulo Astor Soethe. - São Paulo: Edições Loyola, 2002.

A inclusão do outro: estudos de teoria política. Tradução de George Sperber e Paulo Astor Soethe. - São Paulo: Edições Loyola, 2002.

Direito e democracia: entre facticidade e validade, volume II. Tradução Flávio Beno Siebeneichler. - $1^{\mathrm{a}}$ ed. reimpr. - Rio de Janeiro: Tempo Brasileiro, 2011.

. O Estado-nação europeu frente aos desafios da globalização. O passado e o futuro da soberania e da cidadania. Tradução de Antonio Sérgio Rocha. Novos Estudos CEBRAP, n. ${ }^{\circ} 43$, novembro 1995 , p. 91-95.

HOBSBAWM, Eric. A Era dos Extremos: O Breve Século XX (1914-1991). São Paulo: Companhia das Letras, 1995.

JAROCHINSKI SILVA, João Carlos. As migrações internacionais e os seus impactos. In: JUBILUT, Liliana Lyra (Coord.). Direito Internacional Atual. - Rio de Janeiro: Elsevier, 2014, p. 317-339.

JUBILUT, Liliana Lyra; APOLINÁRIO, Silvia Menicucci O. S. A necessidade de proteção internacional no âmbito da migração. Revista Direito GV, São Paulo, v. 11, jan./jun. 2010, p. 317-339.

KANT, Immanuel. A metafísica dos costumes. Trad. por José Lamego. - Lisboa: Edições 70, 2011.

. À paz perpétua. Tradução Marco Zingano. - Porto Alegre, RS: L\&PM, 2010.

LAFER, Celso. A Reconstrução dos Direitos Humanos: um diálogo com o pensamento de Hannah Arendt. - São Paulo: Companhia das Letras, 1988.

LEITE, Rodrigo de Almeida. Os paradoxos do tratamento da imigração ilegal na União Europeia frente à Diretiva de Retorno. Revista Espaço Acadêmico (UEM), n. ${ }^{\circ}$ 108, Maio de 2010, p. 61-70.

MENDONÇA, Felippe. A evolução do conceito jurídico de cidadania no panorama democrático do século XXI. Dissertação (Mestrado) - Universidade de São Paulo, 2012.

NOUR, Soraya. À paz perpétua de Kant: filosofia do direito internacional e das relações internacionais. - $2^{\mathrm{a}}$ ed. - São Paulo: Editora WMF Martins Fontes, 2013.

ONU. Os Excluídos: o mundo desconhecido dos apátridas. Disponível em <https:// nacoesunidas.org/os-excluidos-o-mundo-desconhecido-dos-apatridas $>$. Acesso em: 28 jul. 2016.

PAULO, José Vilema. Falência do Estado-Nação e a Necessidade de Estados Transnacionais: reflexões a partir de Ulrich Beck. Prim@ Facie, João Pessoa, v. 14, n. 26, jan./jun. 2015, p. 01-30.

PEREIRA, Gustavo Oliveira de Lima. Da tolerância à hospitalidade na democracia por vir. Um ensaio a partir do pensamento de Jacques Derrida. Sapere Aude, Belo Horizonte, v. 4, n. 7, $1^{\circ}$ sem. 2013, p. 308-328. 
. Direitos Humanos e Hospitalidade: a proteção internacional para apátridas e refugiados. - São Paulo: Atlas, 2014.

. Interculturalismo \& reconhecimento da diferença: reconstruindo os direitos humanos no itinerário dos apátridas e refugiados. Universitas Relações Internacionais, Brasília, v. 10, n. 1, jan./jul. 2012, p. 69-84.

; SILVA FILHO, José Carlos Moreira da. Direitos humanos, dignidade da pessoa humana e a questão dos apátridas: da identidade à diferença. Direito \& Justiça, Porto Alegre, v. 34, n. 2, jul./dez. 2008, p. 67-81.

RANIERI, Nina Beatriz Stocco. Teoria do Estado: do Estado de Direito ao Estado Democrático de Direito. - Barueri, SP: Manole, 2013.

SAINT-PIERRE, Abbé de. Projeto para Tornar Perpétua a Paz na Europa. Prefácio de Ricardo Seitenfus; tradução de Sérgio Duarte (1 ${ }^{\mathrm{a}}$. edição no Brasil); Brasília: Editora Universidade de Brasília, Instituto de Pesquisa de Relações Internacionais; São Paulo: Imprensa Oficial do Estado de São Paulo, 2003.

SIEYÈS, Emmanuel Joseph. A Constituinte Burguesa: o que é o terceiro Estado? Tradução de Norma Azeredo. - Rio de Janeiro: Liber Juris, 1988.

SORTO, Fredys Orlando. O projeto jurídico de cidadania universal: reflexões à luz do direito de liberdade. Anuario Hispano-luso-americano de Derecho Internacional. Madrid, vol. 20, ene./dic. 2011, p. 103-126. 